\section{Rise in the incidence of abusive head trauma during the COVID-19 pandemic}

\section{INTRODUCTION}

Recent literature highlights a possible increase in child abuse during the coronavirus (SARS-CoV-2) pandemic. ${ }^{1}$ We report a marked increase in the incidence of abusive head trauma (AHT) at our institution.

\section{METHODS}

We reviewed the incidence of suspected AHT between 23 March and 23 April 2020 - the month that the United Kingdom entered a period of national self-isolation-and compared this with the incidence in the previous 3 years.

All children received an ophthalmological assessment, skeletal survey, and computed tomography scan and magnetic resonance imaging of the head and whole spine as part of their investigation. Demographic data and clinical findings were recorded, including parental vulnerabilities and socioeconomic indexing by the Index of Multiple Deprivation.

\section{RESULTS}

Ten children (six boys, four girls; mean age 192 days, range 17 to 401 days) with suspected AHT were seen during this time in comparison with a mean of 0.67 cases per month in the same period over the previous 3 years. This equates to a $1493 \%$ increase in cases of AHT (figure 1). Age did not vary significantly between years (range 0.5 to 13 months).

Prior to presentation, $50 \%$ of patients were colic, $40 \%$ were apnoeic with decreasing consciousness, and 20\% had seizures. Clinical examination revealed retinal haemorrhages $(50 \%)$, extensive

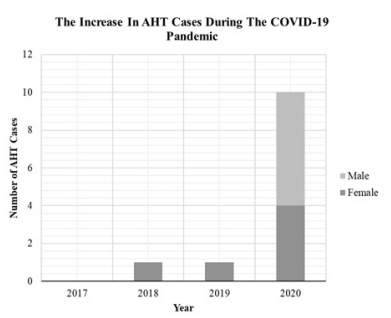

Figure 1 At our centre, we have seen a significant increase in the number of patients presenting with suspected abusive head trauma (AHT) during the lockdown phase of the SARS-CoV-2 pandemic. bruising (50\%), scalp swelling (50\%), and excoriation marks (10\%). Radiological findings included subdural haemorrhage (60\%), cerebral oedema (40\%), parenchymal contusion (40\%), skull fractures (40\%), subarachnoid haemorrhage (30\%), and extracranial fractures (30\%).

All families live in areas with a higher than average Index of Multiple Deprivation (national mean 15 200; cohort mean 19 867), and $70 \%$ of parents had significant underlying vulnerabilities: two had previous criminal histories, three had mental health disorders, and four had financial concerns.

\section{DISCUSSION}

The increase in incidence seen at our institution reflects a rise in domestic abuse in countries enforcing similar social distancing measures. ${ }^{2}$ This sobering figure is likely under-represented due to public avoidance of hospitals at this time. ${ }^{3}$ Notably, two parents in our cohort cited fears of contracting SARS-CoV-2 as a reason for delayed presentation.

International efforts to combat the pandemic focus on social distancing as a means of reducing transmission. The spectrum of socioeconomic and psychosocial challenges associated with such measures can increase parental stress, reflected as increased substance misuse among caregivers-a potential risk in itself. ${ }^{2}$ Our cohort is aligned to the literature in its portrayal of socioeconomic deprivation and parental vulnerability as significant risk factors for abuse, both of which may be exacerbated as a result of the stresses imposed by quarantine measures. The child's increased exposure to their parents and decreased interaction with reporting bodies further heightens this risk. ${ }^{2}{ }^{4}$ The complex links between abuse, mental health, substance misuse, and socioeconomic circumstances are often interdependent and cannot be effectively addressed in isolation. ${ }^{5}$

Hence, in the background of the intensely public SARS-CoV-2 pandemic, a more silent pandemic is occurring, of which the medical community must remain astutely aware.

Jai Sidpra $\odot{ }^{1}{ }^{1}$ Doris Abomeli, ${ }^{2}$ Biju Hameed, ${ }^{3}$
Janice Baker, ${ }^{4}$ Kshitij Mankad ${ }^{5}$
${ }^{1}$ University College London Medical School, University
College London, London, UK
${ }^{2}$ Department of General Paediatrics, Great Ormond
Street Hospital For Children NHS Foundation Trust,
London, UK
${ }^{3}$ Department of Neurology, Great Ormond Street
Hospital For Children NHS Foundation Trust, London,
UK
${ }^{4}$ Department of Child Protection, Great Ormond Street
Hospital For Children NHS Foundation Trust, London,
UK

Jai Sidpra $\odot,^{1}$ Doris Abomeli, ${ }^{2}$ Biju Hameed, ${ }^{3}$

'University College London Medical School, University College London, London, UK

2Department of General Paediatrics, Great Ormond London, UK

${ }^{3}$ Department of Neurology, Great Ormond Street Hospital For Children NHS Foundation Trust, London, Hospital For Children NHS Foundation Trust, London,
${ }^{5}$ Department of Radiology, Great Ormond Street Hospital For Children NHS Foundation Trust, London, UK

Correspondence to Dr Kshitij Mankad, Department of Radiology, Great Ormond Street Hospital For Children NHS Foundation Trust, London WC1N 3JH, UK; drmankad@gmail.com

Twitter Jai Sidpra @JSidpra and Kshitij Mankad @ drmankad

Contributors JS contributed to the study's conception and design, analysis and interpretation of data, and drafted the manuscript. DA and JB contributed to the design of the study, analysis and interpretation of data, and to the revision of the manuscript. $\mathrm{BH}$ and KM contributed to the study's conception and design, analysis and interpretation of data, and the revision of the manuscript

Funding The authors have not declared a specific grant for this research from any funding agency in the public, commercial or not-for-profit sectors.

Competing interests None declared.

Patient consent for publication Not required.

Ethics approval This study was approved by our institutional review board (reference number 2848).

Provenance and peer review Not commissioned; externally peer reviewed.

Data availability statement Data is available from the corresponding author upon reasonable request.

This article is made freely available for use in accordance with BMJ's website terms and conditions for the duration of the covid-19 pandemic or until otherwise determined by BMJ. You may use, download and print the article for any lawful, non-commercial purpose (including text and data mining) provided that all copyright notices and trade marks are retained.

(c) Author(s) (or their employer(s)) 2021. No commercial re-use. See rights and permissions. Published by BMJ.

\section{A Check for updates}

To cite Sidpra J, Abomeli D, Hameed B, et al. Arch Dis Child 2021;106:e14.

Accepted 24 June 2020

Published Online First 2 July 2020

Arch Dis Child 2021;106:e14.

doi:10.1136/archdischild-2020-319872

\section{ORCID iDs}

Jai Sidpra http://orcid.org/0000-0003-1985-5503 Kshitij Mankad http://orcid.org/0001-5979-9337

\section{REFERENCES}

1 Green P. Risks to children and young people during covid-19 pandemic a shift in focus is needed to avoid an irreversible scarring of a generation. $B M J$ 2020;369:m1669.

2 Campbell AM. An increasing risk of family violence during the Covid-19 pandemic: strengthening community collaborations to save lives. Forensic Sci Int 2020:2:100089.

3 National Performance Analysis. A\&E Attendances and Emergency Admissions. Leeds, 2020. https://www. england.nhs.uk/statistics/statistical-work-areas/aewaiting-times-and-activity/

4 Office for national statistics. English indices of deprivation 2019. London, 2019. https://www.gov.uk/ government/statistics/english-indices-of-deprivation2019

5 Department for Education. Characteristics of children in need: 2018 to 2019 England. London, 2019. 